4 (1), 49-58

https://doi.org/10.29044/v4i1p49

\title{
Ego States in the therapeutic relationship and pre- to post- treatment change in Self Ego states
}

\author{
(C) 2012 Davide Ceridono PTSTA-Psychotherapy \& Daniela Viale PTSTA- \\ Psychotherapy
}

\begin{abstract}
This study investigates process and outcome of psychotherapy conducted according to Social-Cognitive Transactional Analysis (SCTA); the perception of Self Ego states, pre- and post- treatment, and of Relational Ego states activated in the therapeutic relationship is studied. Subjects $(N=288)$ were adult clinical outpatients who received 21 sessions of psychotherapy in Prevention and Intervention Clinics connected to four training schools in psychotherapy. Therapists were $3^{\text {rd }}$ and $4^{\text {th }}$ year trainees. Perception of Ego states was studied with self-report questionnaires based on SASB (Benjamin, 1974, 2000; Scilligo \& Benjamin, 1993, Scilligo 2005) by which prototypical Ego states are operationally defined according the SCTA (Scilligo, 2009; De Luca e Tosi, 2011). The results of the preliminary studies show that clients perceive that Free and Protective Ego states in the relationships with therapist are highly activated, and Critical and Rebellious Ego states are very low. Pre- to post-treatment changes of Self Ego states in clients are observed: a growth of Free and Protective Ego states and a reduction of Critical and Rebellious Ego states. This outcome appears to be related to the therapeutic relationship that stimulates Free and Protective Ego states through complementarity during the sessions, and that promotes the development of Free and Protective Ego states by internalization.
\end{abstract}

\section{Introduction}

This study is a part of a broader line of research that has two main aims: 1) to assess the construct validity of the theoretical model of Social-Cognitive Transactional Analysis (SCTA); 2) to monitor systematically the practice conducted by trainees in the Prevention and Intervention Clinics of the schools of psychotherapy associated with the Institute for Research on Intrapsychic and Relational Processes (IRPIR).

In Transactional Analysis the relational paradigm plays a central role, and we believe that the specific subject of
Transactional Analysis is relationships at interpersonal and intrapsychic levels. Therefore we are interested in psychotherapy research that studies the role of therapeutic relationship on the efficacy of psychotherapy, in agreement with conclusion and recommendation about empirically supported therapy relationship (Ackerman et al., 2001; Norcross, 2011).

The present work is an example of study on process and outcome in psychotherapy in term of Ego states, where the focus is on the quality of relationship with other and with self.

In Social-Cognitive Transactional Analysis (SCTA) Ego states are considered especially in their relational aspects that can be observed in intrapsychic and interpersonal processes.

SCTA explains Ego states (ES) with the concept of schemas: structures of meaning that integrate knowledge (Horowitz, 1991; Andersen and Chen, 2002), Ego states are organized by schemas (Scilligo, 2009) which are the bases of representations of self, others, and relationships between self and others. SocialCognitive Transactional Analysis (Scilligo, 2004, 2009; Ceridono, Gubinelli, \& Scilligo, 2009; De Luca \& Tosi, 2011) has developed operational definitions of the concepts of Ego states and instruments of observation based on Structural Analysis of Social Behavior SASB (Benjamin, 1974, 1996, 2003) that permit empirical research and orientation in clinical practice.

SASB is a method to describe interpersonal and intrapsychic behaviour by three dimensions. The first dimension is Focus that distinguishes three different foci of the action: two interpersonal (other and self), and one intrapsychic focus (introject). Examples are: the therapist listens to the client (focus on other); the client discloses self with the therapist (focus on self); the client explores himself (focus introject). The second dimension is Affiliation, that describes the affectivity of the action on a continuum from hostile to friendly. The third dimension is Interdependence, that describes power in 
the action on a continuum from giving power to taking power away in the relationship with other and with self. The poles have different names depending of the type of focus: give autonomy and control for other focus; be separate and submit for the self focus; let self "be" and self-control, for the introject focus. The intersection of the Affiliation (affectivity) and Interdependence (power), for each type of focus, generates three surfaces. Each surface has four wide categories of behaviour.

Combining the two dimensions of Affiliation and Interdependence, we distinguish four categories of Ego states: Free, Protective, Critical, and Rebellious Ego states. In each category Parent, Adult, and Child are also distinguished, and the 12 Ego states are represented in a circumplex. Figure 1 shows the 12 Ego States in the circumplex defined by Affiliation and Interdependence. In Free ES power is given to self/or other in a friendly way; in Protective ES power is taken away from self/or other in a friendly way; in Critical Ego state power is taken away from self/or other in a hostile way; in Rebellious ES power is given to self and/or other in a hostile way.

A distinction is made between Self ES and Relational ES. Self ES are conceptualized as schemas about self, and are operationally described by SASB Introject surface, while Relational ES are schemas about interpersonal relations with others, and are operationally described by SASB Other and Self surface. (Note that the term of the

Figure 1: The 12 Ego States in the circumplex
SASB "Self" expresses a different concept from that of Self Ego state; it refers to a focus of the interpersonal behaviour, while "Self Ego state" refers to intrapsychic processes connected to schemas about self).

The present work aims to analyze process and outcome of psychotherapy conducted according to SocialCognitive Transactional Analysis (SCTA). We studied the perception of Self Ego states pre- and post- treatment and the perception of Relational Ego states activated in the therapeutic relationship.

In a functional perspective, the goal of the treatment can be defined as developing healthy Ego states (Free and Protective ES) and reducing pathological Ego states (Critical and Rebellious ES). In order to achieve this goal the therapeutic relationship has a central role. In SCTA there is a basic assumption about therapeutic relationship: the therapeutic relationship in which therapist activates Free and Protective Ego states stimulates the activation of Free and Protective Ego states in the patient during the session, and facilitates the development of Free and Protective Ego states in the course of time. This assumption is founded on the concepts of complementarity and internalization, concepts that are common to various theories, like object relations (Greenberg \& Mitchell, 1983), interpersonal (Benjamin, 1996), and Transactional Analysis (Berne, 1961). Empirical research, conducted

Give power - give autonomy, separate, let self "be"

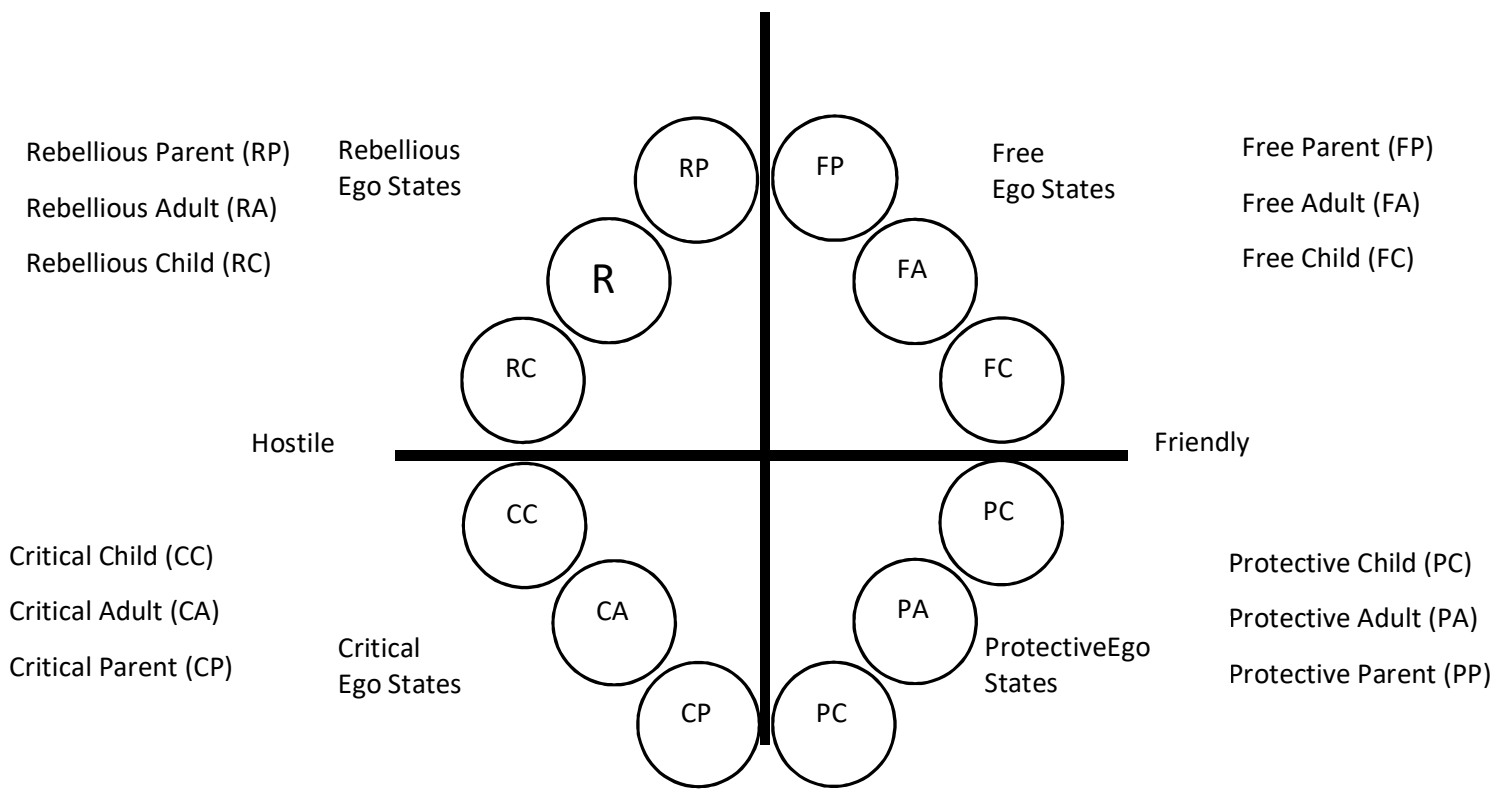

Take away power - control, submit, self-control 
according to therapeutic models similar to TA, like psychodynamic and interpersonal ones, support the impact of therapeutic relationship on clients' introject. Henry, Schacht, \& Strupp (1990) showed that poor outcome cases in psychotherapy were typified by interpersonal behaviour by the therapist that confirmed negative patient introject. Harrist, Quintana, Strupp, \& Henry (1994) found that patients' intrapsychic functioning became more similar to therapist-patient relationship over the course of therapy.

\section{Hypothesis}

In the present work we hypothesized that posttreatment Free and Protective Self Ego states have higher level and Critical and Rebellious Self Ego states have lower level in comparison with pre-treatment, consistent with the aims of the treatment.

We hypothesized that this outcome is related to a therapeutic relationship in which Free and Protective Relational Ego States are highly activated by therapist and client, and in which there is also a complementarity between Free and Protective ES of therapist focused on client and Free and Protective ES of client focused on self in relationship with therapist.

In particular, we hypothesized that pre- to posttreatment change in Self ES is promoted by introjection of the Relational ES of therapist focused on the client; the client learns to treat himself like therapist treated him. Thus we expected that post-treatment Self ES would be correlated to correspondent Relational ES of therapist more than pre- treatment Self ES.

We choose to assess the process from the patient's perspective because we found that this perspective has the stronger correlation with outcome, as processoutcome research suggest.

We also investigated the relation between the client's perception of Free Adult and Protective Adult Ego states of the therapist focused on the client, and the outcome in terms of Self Ego states. We hypothesized that in clients that perceive high levels of Free Adult and Protective Adult Relational ES in therapist focused on him, Free and Protective Self ES at post-treatment are more developed and Critical and Rebellious Self ES are less developed than in clients that perceive low levels of Free Adult and Protective Adult ES in therapist. These two Adult Relational ES were chosen because they were perceived by clients as the two that were more activated, moreover they had good correlations with post treatment Self Ego state of the client, and they represent two main function of the therapist in relationship with client.

Free Adult focused on client is described by listening, emphatic understanding, and confirming of the client. This ES stimulates the client disclosing and contact with self. Free Adult should be important for client feeling safe and to develop alliance. The interpersonal dimensions of Free Adult are to give power (give freedom) to the client in a friendly way.
Protective Adult focused on the client is described by analyzing and constructively stimulating the client to think. This ES stimulates the client to pay attention to new information and reflect on it. Protective Adult should be important for decontamination. The interpersonal dimensions of Protective Adult are to take away power from the client (a moderate control) in a friendly way.

\section{Subjects and Instruments}

Subjects were adults $(\mathrm{N}=288)$, male $(25 \%)$ and female (75\%), clinical outpatients from Prevention and Intervention Clinics of four training schools in psychotherapy that are associated with IRPIR.

Subjects received a 21 sessions psychotherapy conducted according to the SCTA model. Therapy had a contractual approach that included a general contract about goal, stipulated with client.

Therapists were psychologists, $3 \mathrm{rd}$ and 4 th year trainees in psychotherapy that also were CTA trainees, in continuing supervision with TSTAs and PTSTAs.

Perception of Ego states was studied with self-report questionnaires based on SASB (Benjamin, 1974, 2000; Scilligo \& Benjamin, 1993, Scilligo, 2005) that we use to measure the operational definition of the prototypical Ego states according to Social-Cognitive TA (Scilligo, 2009; Ceridono, Gubinelli, \& Scilligo, 2009; De Luca \& Tosi, 2011).

Clients rated 12 prototypical Self Ego states with Anint $A$, a 36 items questionnaire based on Introject surface of SASB. Each item was rated on a scale ranging from 0 (never, not at all) to 10 (always, completely).

Clients also rated 24 prototypical Relational Ego states of therapist and of self, perceived in the therapeutic relationship, with Anint $D$, a 144 items questionnaire based on Other and Self surfaces of SASB. Each item was rated on a scale ranging from 0 (never, not at all) to 10 (always, completely). In the present work are studied the 12 Relational ES of the therapist focused on the client, and the 12 Relational ES of the client focused on self in the relationship with the therapist.

Scores resulting from each set of 12 scales of the Ego states can be represented in graphical form analogous to the classical egogram.

\section{Ethical Issues}

Consent. All clients gave consent to use data from questionnaires for clinical and research use.

Confidentiality. Personal data and information about sessions were protected by professional confidentiality and discussed only in the context of supervision.

Privacy. The use of a code system prevented identification of clients to all who accessed the data, and procedures according to national law about privacy were followed. 
Principles of respect and protection of the client. We excluded the possibility of creating a control group with a waiting list, to prevent any client waiting too long between the request for help and the start of treatment.

\section{Method}

Self perception (Self Ego states) was rated at intake before psychotherapy (pre-treatment) and in the last session of psychotherapy (post-treatment).

The perception of therapeutic relationship (Relational Ego states) was rated by clients after the 8th session (between 8th and 9th). At this time therapeutic alliance should have been established.

To test the hypothesis some preliminary studies were performed. Presented results come from four of them.

In the first study, pre- to post-treatment differences of mean scores on scales of 12 Self Ego states were tested with Student $T$ test for dependent samples.

The second study were calculated means scores of the scales of 24 Relational Ego states activated in the therapeutic relations, from the client perspective.

In the third study correlations (Pearson's $r$ ) were calculated between Ego state variables.

In the fourth study factorial ANOVA was performed for two factors (two-level with cut-off at the median): Free Adult and Protective Adult Ego states of therapist in relational focus on client, rated by client; dependent variables were 12 Self Ego states rated by client at posttreatment.

\section{Results}

Pre- and post-treatment Self Ego States

Figure 2 shows pre- and post-treatment Self Ego states profiles of the sample, based on the means of the 12 scales of Anint A.

The pre-treatment profile of Self ES indicate a dysfunctional condition where Free ES have too low activation and Critical and Rebellious are too activated, also Protective Parent is a little high.

The post-treatment profile suggest a wellness condition with high Free and Protective ES and low Critical and Rebellious ES. In particular Free Adult and Free Child and Protective Child and Protective Adult are high, Free Parent and Protective Parent are middle and balanced. Critical Adult, Critical Child, and Rebellious ES are low.

Nevertheless, Critical Parent has a middle level that suggests there is still some imperative self control that may limit the health functioning.

Table 1 reports means and standard deviation of 12 Self ES pre- and post-treatment for the group, and Student T test summary. The results of the study of pre- to posttreatment difference show a growth of all Free Ego states and of Protective Child and Protective Adult Ego states. Protective Parent decrease, and there is a reduction of all Critical and Rebellious Ego states.

All the changes are statistically significant $(p<0.01 ; A P$ $p=0.01$ ). These changes suggest an activation of Self Ego states in the direction of treatment goal. The decrease of Protective Parent is coherent with the other changes, because in pre-treatment this level was high.

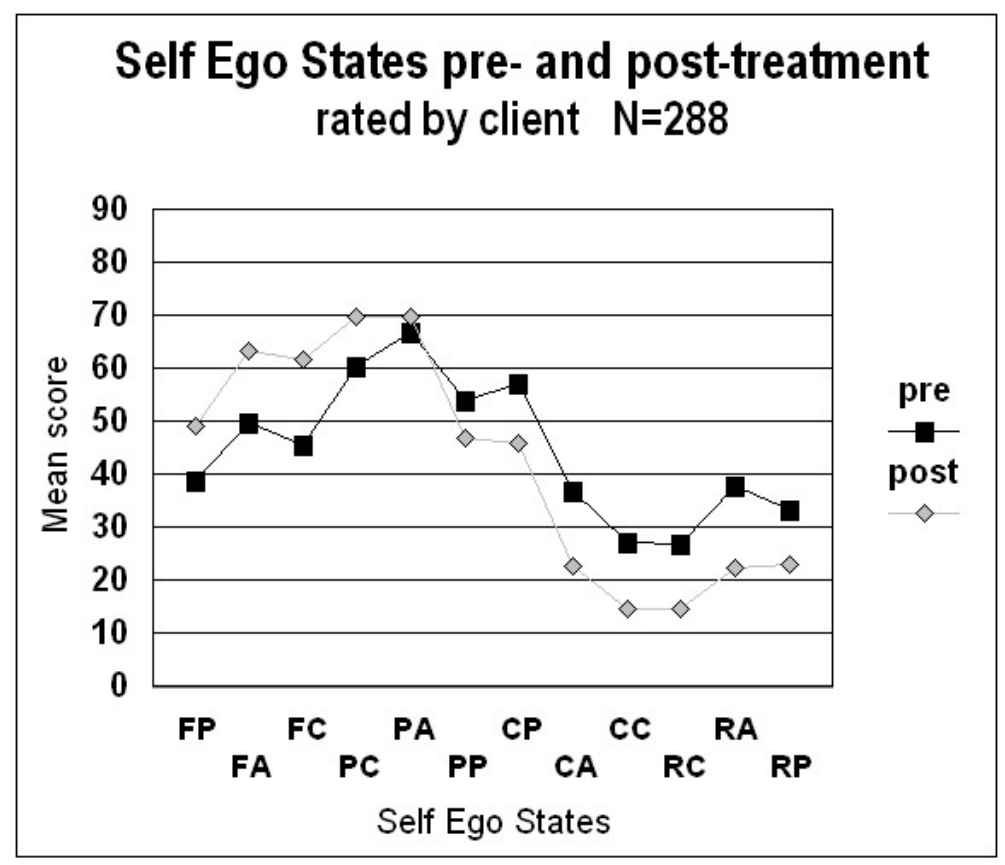

$2^{\text {nd }}$ EATA TA Research Conference 2012: Proceedings published as 
Table 1: means and standard deviation of 12 Self ES pre-and post-treatment, and Student T test summary

\begin{tabular}{|c|c|c|c|c|c|c|c|c|}
\hline SelfES & Mean & Std.Dv & $\mathrm{N}$ & Diff . & Std.Dv . & $\mathrm{t}$ & Df & $p$ \\
\hline FP pre & 38.99 & 19.54 & & & & & & \\
\hline FP post & 49.22 & 18.44 & 288 & -10.23 & 21.76 & -7.98 & 287 & 0.000 \\
\hline FA pre & 49.97 & 19.73 & & & & & & \\
\hline FA post & 63.43 & 18.29 & 288 & -13.46 & 21.69 & -10.53 & 287 & 0.000 \\
\hline FC pre & 45.73 & 20.97 & & & & & & \\
\hline FC post & 61.92 & 19.83 & 288 & -16.19 & 21.79 & -12.61 & 287 & 0.000 \\
\hline PC pre & 60.56 & 17.05 & & & & & & \\
\hline $\mathrm{PC}$ post & 69.72 & 14.58 & 288 & -9.17 & 16.23 & -9.59 & 287 & 0.000 \\
\hline PA pre & 66.78 & 16.94 & & & & & & \\
\hline PA post & 69.72 & 15.24 & 288 & $-2,94$ & 19.35 & -2.58 & 287 & 0.010 \\
\hline PP pre & 54.13 & 20.02 & & & & & & \\
\hline PP post & 46.98 & 19.19 & 288 & 7.15 & 23.56 & 5.15 & 287 & 0.000 \\
\hline CP pre & 57.18 & 19.68 & & & & & & \\
\hline CP post & 45.94 & 19.76 & 288 & 11.24 & 24.92 & 7.65 & 287 & 0.000 \\
\hline CA pre & 37.00 & 20.25 & & & & & & \\
\hline CA post & 22.89 & 18.20 & 288 & 14.11 & 20.61 & 11.62 & 287 & 0.000 \\
\hline CC pre & 27.22 & 22.22 & & & & & & \\
\hline CC post & 14.57 & 17.96 & 288 & 12.65 & 20.07 & 10.70 & 287 & 0.000 \\
\hline $\mathrm{RC}$ pre & 26.90 & 21.20 & & & & & & \\
\hline $\mathrm{RC}$ post & 14.68 & 15.69 & 288 & 12.22 & 19.57 & 10.60 & 287 & 0.000 \\
\hline RA pre & 37.84 & 23.59 & & & & & & \\
\hline RA post & 22.43 & 18.75 & 288 & 15.41 & 22.21 & 11.77 & 287 & 0.000 \\
\hline RP pre & 33.26 & 20.37 & & & & & & \\
\hline RP post & 23.13 & 17.69 & 288 & 10.14 & 20.03 & 8.59 & 287 & 0.000 \\
\hline
\end{tabular}

Ego States in the therapeutic relationship

Table 2 reports descriptive statistics of the 12 Relational Ego states of therapist focused on client and of the 12 Relational Ego states of the client focused on self in the relationship with the therapist. Table 3 reports the values of $r$ of the diagonals of matrix of correlations between the corresponding Relational Ego States of therapist and client. Data are collected from the perspective of the client, who rated Ego states with Anint D. Figure 3 shows the two profiles of the means of the Relational ES of therapist and client.

The results show that all Free Ego states, and Protective Child and Protective Adult Ego states, both of therapist focused on client and of client focused on self, have high level of activation (55, 5-81).
Protective Parent of therapist has a low activation (21, 6 ) and Protective Parent of the client has a middle activation $(42,1)$. All Critical and Rebellious Ego states of therapist and client are very low. The most activated Ego states are Free Adult and Protective Adult, both in therapist and client. This indicates a relationship in which: therapist listens and understands with empathy (FA) and client discloses self and expresses (FA); therapist analyzes and constructively stimulates (PA) and client accepts stimuli, reflects and learns (PA). Level of ES of therapist and client are almost the same, except for Protective Child and Protective Parent that are higher in the client (PC: $+10,5$; PP: $+20,5)$. Clients perceive a high satisfaction (PC: 66) in the relationship with the therapist as they perceive the therapist moderately affectionate (PC: 55,5$)$. Clients perceive also 
Table 2: Descriptive statistics of 12 Relational ES of the therapist focused on the client and 12 Relational ES of client focused on self in relationship with therapist

\begin{tabular}{|c|c|c|c|c|c|c|c|c|c|c|c|c|}
\hline & \multicolumn{12}{|c|}{ Relational Ego States of client focused on client } \\
\hline & FP & FA & FC & PC & PA & PP & $\mathrm{CP}$ & CA & CC & $\mathrm{RC}$ & RA & RP \\
\hline $\mathrm{N}$ valid & 288 & 288 & 288 & 288 & 288 & 288 & 288 & 288 & 288 & 288 & 288 & 288 \\
\hline Mean & 59.9 & 81 & 69.3 & 55.5 & 71.4 & 21.6 & 7.2 & 4.7 & 1.9 & 4.3 & 3.3 & 11.6 \\
\hline Min & 0 & 13.3 & 0 & 0 & 20 & 0 & 0 & 0 & 0 & 0 & 0 & 0 \\
\hline Max & 100 & 100 & 100 & 100 & 100 & 100 & 43.3 & 56.7 & 46.7 & 55 & 36.7 & 90 \\
\hline \multirow[t]{3}{*}{ S.D. } & 21.5 & 15.2 & 19.5 & 22.8 & 16 & 24.6 & 10.2 & 9.9 & 6.2 & 9 & 7.4 & 15.6 \\
\hline & \multicolumn{12}{|c|}{ Relational Ego States of client focused on self } \\
\hline & FP & FA & FC & PC & PA & PP & $\mathrm{CP}$ & CA & CC & $\mathrm{RC}$ & RA & $\mathrm{RP}$ \\
\hline $\mathrm{N}$ valid & 288 & 288 & 288 & 288 & 288 & 288 & 288 & 288 & 288 & 288 & 288 & 288 \\
\hline Mean & 58.9 & 81.5 & 73.3 & 66 & 74.2 & 42.1 & 8.7 & 7 & 4.9 & 3.1 & 8.6 & 7.4 \\
\hline Min & 0 & 0 & 0 & 0 & 0 & 0 & 0 & 0 & 0 & 0 & 0 & 0 \\
\hline Max & 100 & 100 & 100 & 100 & 100 & 100 & 70 & 60 & 46.7 & 40 & 66.7 & 65 \\
\hline S.D. & 16.1 & 14.8 & 18.4 & 21.2 & 19.3 & 20.1 & 13.6 & 11.4 & 8.9 & 7.3 & 12.2 & 13 \\
\hline
\end{tabular}

Table 3: Correlations between the corresponding Relational Ego states of therapist and client

\begin{tabular}{|l|l|l|l|l|l|l|l|l|l|l|l|l|}
\hline & FP & FA & FC & PC & PA & PP & CP & CA & CC & RC & RA & RP \\
\hline$r$ & $0.37^{*}$ & $0.42^{*}$ & $0.51^{*}$ & $0.51^{*}$ & $0.49^{*}$ & $0.44^{*}$ & $0.62^{*}$ & $0.46^{*}$ & $0.53^{*}$ & $0.62^{*}$ & $0.60^{*}$ & $0.21^{*}$ \\
\hline$* p<.05$ & \multicolumn{10}{|l|}{} & &
\end{tabular}

Figure 3: The two profiles of the means of the Relational ES of therapist and client

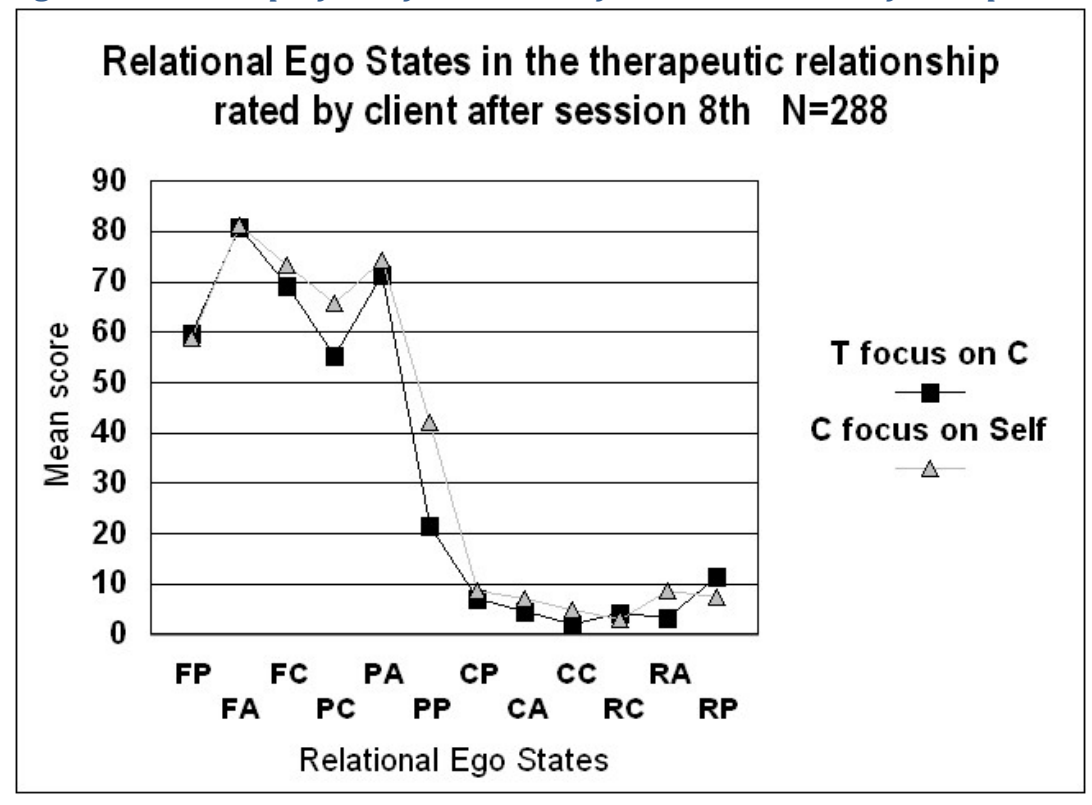


moderate friendly submission (PP: 42,1 ), that is more elevated that the corresponding friendly control from the therapist, that is low (PP: 21, 6). All this suggests that clients perceive the therapeutic relationship as characterized by friendly differentiation and moderate friendly enmeshment. Moreover, the little differences and the significant positive correlations between the corresponding Relational Ego states of therapist and client, indicate that clients perceive a strong complementarity in the relationship with the therapist.

Relationship between Relational Ego State in therapy and post-treatment Self Ego State Relationship between Ego state variables was explored by correlation of scores of Ego State scales. Table 4 reports the values of $r$ of the diagonals of three matrices of correlation (between corresponding Ego States):

a. between pre-treatment and post-treatment 12 Self ES of client;

b. between pre-treatment 12 Self ES of client, and 12 Relational ES of therapist focused on client in treatment;

c. between 12 Relational ES of therapist focused on client in treatment, and post-treatment 12 Self ES of client.

Bold coefficients are statistically significant $(p<.05)$. An overview of $r$ coefficients reveals stronger correlations between pre- and post-treatment Self ES ( $r$ is significant for all the Ego states). This result suggests that outcome has a strong relation with characteristics of the client. The clients change, and at the same time maintain coherence with pre-treatment conditions. Nevertheless correlations between post-treatment Self ES of client and Relational ES of therapist are all significant, and are higher than between pre-treatment Self ES and Relational ES of therapist. The latter are significant only for five Ego States. Furthermore correlation between Self ES and Relational ES are lower than correlation between pre and post Self ES. This result, combined with the analysis of the mean scores of the profiles of Ego states, suggests that post-treatment profiles of Self ES of clients tend to be more similar to the therapist's profile of Relational Ego states, than they were before treatment, in particular for Free ES, for Protective Child, for Critical Parent, and for Rebellious Adult and Parent. In other words, it seems that the more the client perceives the activations of Relational ES of therapist, the more she/he activates the corresponding Self ES with themselves.

Significant relationship between perception of Relational Ego State in therapy and post-treatment Self Ego State emerged from ANOVA.

Means of the 12 Self ES of clients in the factorial ANOVA are reported in Table 5. In columns there are dependent variables: the 12 Self Ego states rated by client at posttreatment. Means are by levels ( $1=$ low, $2=$ high) of the two factors: Relational Free Adult ES ( $\mathrm{rFA})$ and Relational Protective Adult ES ( $\mathrm{rPA}$ ) of the therapist focused on client. Results of ANOVA are reported for rFA, rPA and rFA x rPA in Table 6. (In rows dependent variables: 12 Self Ego states rated by client at posttreatment).

Results of ANOVA shows significant difference in nine Self ES at post-treatment for the factor Relational Free Adult. In addition, there are two significant differences for the factor Relational Protective Adult, and no significant difference for the interactions of the two factors. Clients that perceive high level of activation of Relational Free Adult of the therapist, perceive at posttreatment higher Free Self ES and Protective Child and lower Critical Adult, Critical Child and Rebellious Self ES in comparison with clients that perceive low Relational Free Adult of the therapist. The perception of high level of Relational Protective Adult of the therapist is related to higher level of Self Protective Adult and lower Self Critical Child in clients at post-treatment.

Table 4: Values of $r$ of the diagonals of three matrices of correlation (between corresponding Ego States): a) between pre-treatment and post-treatment 12 Self ES of client; b) between pre-treatment 12 Self ES of client, and 12 Relational ES of therapist focused on client in treatment; c) between 12 Relational ES of therapist focused on client in treatment, and post-treatment 12 Self ES of client (significant $p<.05$ in bold).

\begin{tabular}{|l|l|l|l|l|l|l|l|l|l|l|l|l|}
\hline & FP & FA & FC & PC & PA & PP & CP & CA & CC & RC & RA & RP \\
\hline $\begin{array}{l}\text { a. S.ES pre \& } \\
\text { S.ES post }\end{array}$ & 0.34 & 0.35 & 0.43 & 0.48 & 0.28 & 0.28 & 0.20 & 0.43 & 0.52 & 0.47 & 0.47 & 0.45 \\
\hline $\begin{array}{l}\text { b. S.ES pre \& } \\
\text { Rel ES ter }\end{array}$ & -0.01 & 0.02 & 0.11 & 0.09 & 0.16 & 0.13 & 0.06 & 0.19 & 0.14 & 0.26 & 0.11 & 0.11 \\
\hline $\begin{array}{l}\text { c. Rel ES ter \& } \\
\text { S.ES post }\end{array}$ & 0.15 & 0.19 & 0.23 & 0.20 & 0.16 & 0.22 & 0.24 & 0.27 & 0.24 & 0.39 & 0.18 & 0.24 \\
\hline \begin{tabular}{l} 
In bold $p<.05$ \\
\hline
\end{tabular}
\end{tabular}


Table 5: Means of the 12 Self ES of clients at post-treatment in the factorial ANOVA by levels of Relational Free Adult ES (rFA) and Relational Protective Adult ES (rPA) of the therapist focused on client (Levels: 1=low; 2=high)

\begin{tabular}{|c|c|c|c|c|c|c|c|c|c|c|c|c|c|c|c|}
\hline & \multicolumn{2}{|c|}{$\begin{array}{l}\text { Level } \\
\text { of }\end{array}$} & $\mathrm{N}$ & FP & FA & FC & PC & PA & PP & $\mathrm{CP}$ & CA & $\mathrm{CC}$ & $\mathrm{RC}$ & RA & $\mathrm{RP}$ \\
\hline Total & & & 288 & 49.22 & 63.43 & 61.92 & 69.72 & 69.72 & 46.98 & 45.94 & 22.89 & 14.57 & 14.68 & 22.43 & 23.13 \\
\hline rFA & 1 & & 131 & 45.90 & 58.63 & 56.28 & 64.87 & 68.45 & 49.43 & 48.19 & 27.38 & 19.11 & 18.80 & 26.74 & 26.45 \\
\hline rFA & 2 & & 157 & 52.00 & 67.43 & 66.62 & 73.77 & 70.79 & 44.94 & 44.06 & 19.15 & 10.79 & 11.24 & 18.83 & 20.35 \\
\hline rPA & 1 & & 149 & 47.00 & 61.01 & 59.49 & 67.25 & 67.72 & 47.28 & 46.26 & 25.41 & 17.96 & 17.18 & 23.62 & 25.00 \\
\hline rPA & 2 & & 139 & 51.61 & 66.02 & 64.53 & 72.37 & 71.87 & 46.65 & 45.59 & 20.19 & 10.94 & 12.00 & 21.15 & 21.12 \\
\hline rFA rPA & 1 & 1 & 91 & 44.76 & 56.81 & 54.98 & 63.08 & 67.22 & 50.05 & 48.46 & 28.53 & 21.21 & 20.19 & 26.81 & 27.36 \\
\hline rFA rPA & 1 & 2 & 40 & 48.50 & 62.75 & 59.25 & 68.94 & 71.25 & 48.00 & 47.58 & 24.75 & 14.33 & 15.63 & 26.58 & 24.38 \\
\hline rFA rPA & 2 & 1 & 58 & 50.52 & 67.59 & 66.55 & 73.79 & 68.51 & 42.93 & 42.82 & 20.52 & 12.87 & 12.46 & 18.62 & 21.29 \\
\hline rFA rPA & 2 & 2 & 99 & 52.86 & 67.34 & 66.67 & 73.76 & 72.12 & 46.11 & 44.78 & 18.35 & 9.56 & 10.53 & 18.96 & 19.80 \\
\hline
\end{tabular}

Table 6: Results of ANOVA for Relational Free Adult, Relational Protective Adult, and interaction of the two factors (significant $p<.05$ in bold italics).

\begin{tabular}{|c|c|c|c|c|c|c|c|c|c|c|}
\hline & \multicolumn{3}{|c|}{ Rel. Free Adult } & \multicolumn{3}{|c|}{ Rel. Protective Adult } & \multicolumn{3}{|c|}{$r F A \times r P A$} & \multirow[b]{2}{*}{ Error } \\
\hline & MS & $\mathrm{F}$ & $p$ & MS & $\mathrm{F}$ & $p$ & MS & $\mathrm{F}$ & $p$ & \\
\hline FP & 1616.3 & 4.866 & 0.028 & 584.2 & 1.759 & 0.186 & 30.7 & 0.092 & 0.762 & 332.2 \\
\hline FA & 3727 & 11.826 & 0.001 & 511 & 1.623 & 0.204 & 604 & 1.915 & 0.167 & 315 \\
\hline $\mathrm{FC}$ & 5692.2 & 15.446 & 0.000 & 303.4 & 0.823 & 0.365 & 272.4 & 0.739 & 0.391 & 368.5 \\
\hline PC & 3814 & 19.917 & 0.000 & 537 & 2.803 & 0.095 & 548 & 2.862 & 0.092 & 191 \\
\hline PA & 74 & 0.321 & 0.572 & 924 & 4.018 & 0.046 & 3 & 0.012 & 0.913 & 230 \\
\hline PP & 1282.6 & 3.511 & 0.062 & 20 & 0.055 & 0.815 & 432.7 & 1.185 & 0.277 & 365.3 \\
\hline $\mathrm{CP}$ & 1126.8 & 2.891 & 0.090 & 18.7 & 0.048 & 0.827 & 127.6 & 0.327 & 0.568 & 389.8 \\
\hline CA & 3282.1 & 10.395 & 0.001 & 559.4 & 1.772 & 0.184 & 41.3 & 0.1309 & 0.718 & 315.7 \\
\hline $\mathrm{CC}$ & 2712.31 & 8.964 & 0.003 & 1638.52 & 5.415 & 0.021 & 200.59 & 0.6629 & 0.416 & 302.57 \\
\hline $\mathrm{RC}$ & 2599.21 & 11.215 & 0.001 & 665.87 & 2.873 & 0.091 & 110.11 & 0.4751 & 0.491 & 231.77 \\
\hline RA & 3951.6 & 11.641 & 0.001 & 0.2 & 0.001 & 0.982 & 5 & 0.0149 & 0.903 & 339.4 \\
\hline $\mathrm{RP}$ & 1789.8 & 5.853 & 0.016 & 317.3 & 1.038 & 0.309 & 35.2 & 0.115 & 0.735 & 305.8 \\
\hline
\end{tabular}

A representation of the mean profiles of post-treatment Self ES of the four groups of clients defined by the two factors is presented in Figure 4. Clients that perceive therapist high in Relational Free Adult and high in Relational Protective Adult have a Self ES profile with Free ES, Protective Child, and Protective Adult more developed, and Critical and Rebellious ES less developed in comparison with client that perceive therapist low on both Free Adult and Protective Adult. The other two groups present intermediate profiles.

The study of client's Self Ego state in post-treatment, in relationship to the client's perception of the two types of Adult ES activated by the therapist, points to the Free Adult ES being associated with more activation of healthy Self ES than the Protective Adult ES. This fact confirms the main importance of the therapist relating to clients in an accepting and empathetic way, being separate and friendly, and also stimulating the clients in a protective way.

Our results are also similar to those of research that used SASB to assess therapeutic relationship and prepost change in self perception (Harrist, Quintana, Strupp, \& Henry, 1994). 


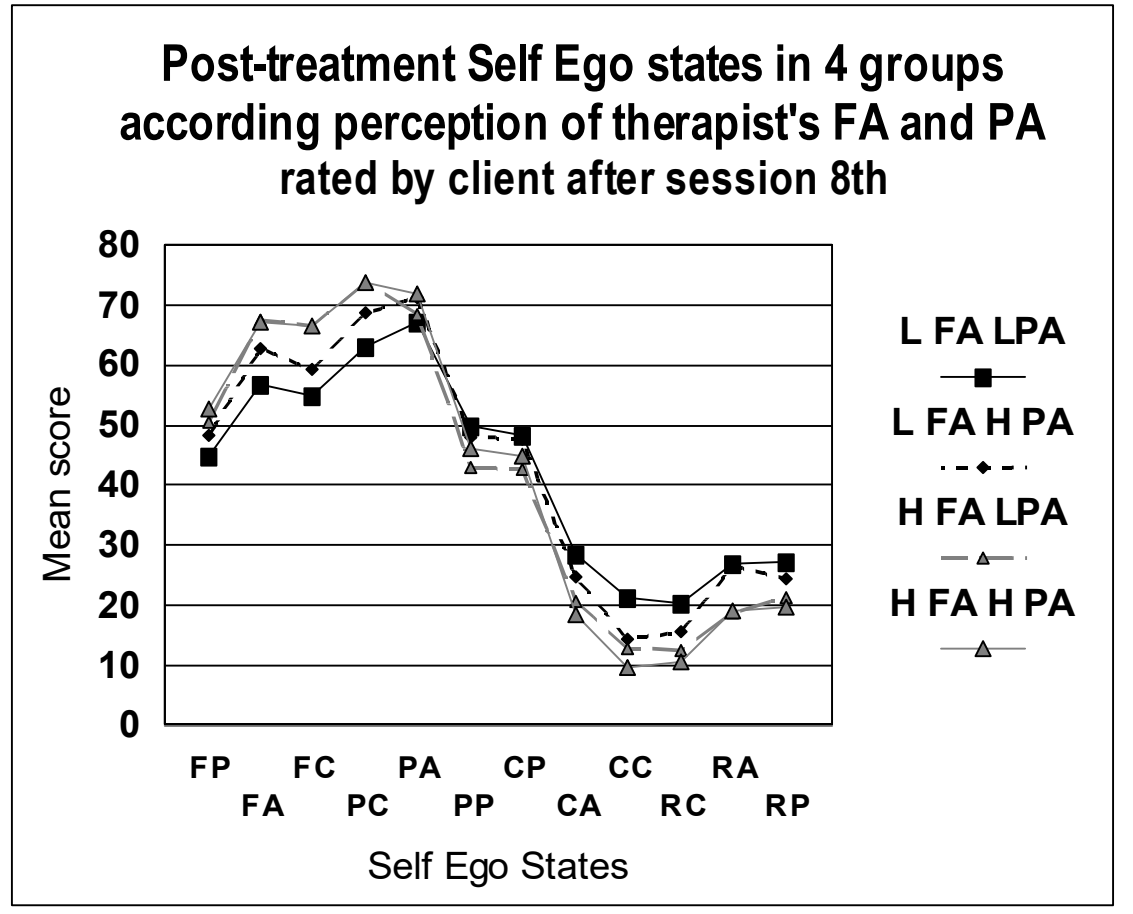

Moreover, results on the client's perception of the therapeutic relationship indicate that psychotherapy conducted in our clinics is consistent with the fundamental principle of SCTA psychotherapy: the therapeutic relationship is a prerequisite preceding any technical intervention. It also seems that the therapist is perceived in an OK-OK position.

In the absence of a control group, our results do not allow it to be argued that the observed changes are caused by therapy. However, this result shows that the changes are consistent with the SCTA basic assumption about therapeutic relationship: the therapeutic relationship in which the therapist activates Free and Protective Ego states stimulates the activation of Free and Protective Ego states in the patient during the session, and facilitates the development of Free and Protective Ego states in the course of time. This assumption finds empirical support in several studies on psychotherapy (Norcross, 2011).

In addition, due to other methodological limitations such as no systematic post-treatment assessments with different instruments and different perspectives, we may question both the validity of the results, and their clinical significance. However, our results are coherent with what we have observed in clinical practice and supervision about the same clients who have been the subjects of research. Furthermore $18 \%$ of the sample have also been studied as a case study for the CTA exam.

\section{Conclusion}

This group research on Ego states in psychotherapy provides us with information on general phenomena considered at a high level of abstraction, and it adds to other research to provide support for the construct validity of the theoretical model of SCTA. The results obtained and the limitations encountered have supported the idea to continue in this line of research, developing a new protocol that includes the study of the therapeutic relationship from three different perspectives: the client, the therapist, the outside observer. In the new research protocol we included the CORE-OM (Evans et al., 2002) for outcome measure, and the evaluation of Ego states also in the follow-up.

The operational definition of Ego states adopted in SCTA allows us to do research using the same tools we use in clinical practice and supervision to analyze Ego states and transactions, and to describe dysfunctional and healthy relational processes. In particular, the SASB model, allows us to collect both self-report data with questionnaires, and observational data with a method of encoding audio and video recordings. This gives us the opportunity to bridge the gap between research and clinical practice, and to integrate single case research with group research. In this direction we plan to make further studies on the processes of change, at more specific levels of analysis, studying intensive single cases and small groups of subjects. 
Despite its limits, this work helps to document empirically Transactional Analytic psychotherapy. Finally, the results have also provided valuable feedback about psychotherapy conducted by our trainees in the clinics of the schools of psychotherapy training, and allowed us to feed the virtuous circle of practiceresearch-theory-training.

\section{References}

Ackerman, J. S., Benjamin, L. S., Beutler, L. E., et al., (2001). Empirical supported therapy relationships: conclusion and recommendations of the division 29 task force. Psychotherapy, 38, 495-497.

Andersen, S. M., and Chen, S. (2002). The relational Self: an interpersonal social-cognitive theory. Psychological Review, 109, 619-645.Benjamin, L.S. (1974). Structural analysis of social behavior (SASB). Psychological Review, 81, 392-425.

Benjamin, L. S. (1996). Interpersonal theory of personality disorders. In J. F. Clarkin and M. F. Lenzenveger (Eds.) Theories of Personality Disorders. New York: Guilford Press.

Benjamin, L. S. (2000). Intrex user's manual. Salt Lake City: University of Utah.

Benjamin, L. S. (2003). Interpersonal Reconstructive Therapy. Promoting change in non-responders. New York: Guilford Press.

Berne, E. (1961). Transactional Analysis. A systematic individual and social psychiatry. New York: Grove Press.

Ceridono, D., Gubinelli, M., Scilligo, P. (2009). Gli Stati dell'lo nell'Analisi Transazionale Socio-Cognitiva: la definizione dimensionale. Idee in Psicoterapia, 2, № 2, 85-100.

De Luca, M.L., Tosi , M.T. (2012). Social-Cognitive Transactional Analysis : An introdution to Pio Scilligo's model of Ego states. Transactional Analysis Journal, 41, No 3, 206-220.
Evans, C., Connel, J., Barkam, M., Margison, F., McGrath, G., Mellor-Clark, J., and Audin, K. (2002). Toward a standardised brief outcome measure : psychometric properties and utility of CORE-OM. British Journal of Psychiatry, 180, 51-60.

Greenberg, J. R., Mitchell, S. A. (1983). Object relations in psychoanalytic theory. Cambridge: Harvard University Press.

Harrist, R.S., Quintana, S.M., Strupp, H.H., and Henry, W.P. (1994). Internalization of interpersonal process in time limited dinamic psychotherapy. Psychotherapy, 31, 49-57.

Henry, W.P., Schacht, T.E., and Strupp, H.H. (1990). Patient and therapist introject, interpersonal process, and differential psychotherapy outcome. Journal of Consulting and Clinical Psychology, 58, 768-774.

Horowitz, M. J., (Ed.) (1991). Person schemas and maladaptive interpersonal patterns. Chicago: The University of Chicago Press.

Norcross, J. C. Ed (2011). Psychotherapy relationship that work $\left(2^{\text {nd }}\right.$ ed.). New York : Oxford University Press.

Scilligo, P. (2000). Il questionario ANINT-A36: uno strumento per misurare la percezione di sé. Psicologia Psicoterapia e Salute, 6, 1-35.

Scilligo, P. (2004). Defining Ego States in relational and developmental terms. EATA Newsletter, n. 79, February, 7-13.

Scilligo, P. (2005). La nuova sinfonia dei molti Sé. Roma: LAS.

Scilligo, P. (2009). Analisi Transazionale Socio Cognitiva. Roma: LAS.

Scilligo, P., and Benjamin, L. S. (1993). L'analisi strutturale del comportamento interpersonale. In Scilligo, P. (a cura di), Sistemi intrapsichici e interpersonali. Roma: IRPIR.

Scilligo, P., \& De Luca, M. L. (1997). Copione del terapeuta e alleanza terapeutica. Psicologia Psicoterapia e Salute, 3, 1-20. 